\title{
DOMESTIC FOOD CONSUMPTION AND EXPENDITURE IN BRITAIN
}

$\mathrm{T}$

HE recently issued annual report of the National

Food Survey Committee for 1958 is the ninth in the series of surveys, begun in 1950, of food consumption and expenditure on food in private households in the United Kingdom*. During 1958, 8,611 records were compiled from 827 polling districts in England, Wales and Scotland. The survey methods remained unchanged. Information was collected on all foods purchased or brought into the household during one week, but, as before, soft drinks, sweets, ice-cream and snacks were not included, and full details of meals taken away from home not obtained; an allowance has been made for these when the nutritive value of the diet is assessed. Records are no longer sought of changes of larder stocks, these being largely unnecessary for the lowincome groups in which daily shopping is traditional. In the higher-income groups bulk purchasing of some items is more frequent, and a large number of households would have to be surveyed to obtain a statistically correct record.

While the survey is thus incomplete on the food consumption side, it provides much valuable information on the expenditure on food and eating habits of the community, set out in a series of well-presented tables which enable the expenditure on many types of foods by families differing in social class, composition and location to be compared.

For Britain as a whole, weekly expenditure on food (with allowances for free and home-grown food) rose from $29 s$. $1 d$. per head per week in 1957 to $29 s .4 d$. in 1958. This small increase is attributed to higher seasonal prices. Since 1954, when rationing ceased, the percentage rise in expenditure on food has increased year by year. The report notes that "the average calorie intake of the population has reached such a level that there is little scope for increases in the quantum of purchases except through improvements in quality, service, processing and packing or through increased wastage".

Little change has occurred since 1954 in expenditure on the broad food groups, but within these groups there has been a significant increase in purchases of processed foods such as cakes and hiscuits and certain kinds of processed meat, fish, vegetables and fruit. The consumption of butter continues to rise and that of margarine to fall. The steady decrease in expenditure on bread has halted and shows a

- Ministry of Agriculture, Fisheries and Food. Domestic Food Consumption and Expenditure, 1958 : Annual Report of the National Food Survey Committee. Pp. vii + 185. (Iondon: H.M. Stationery Office, 1960.) 108, net. slight rise, mainly due to the purchase of dearer types of bread.

On the average there has been little change in the nutritive value of the average British diet since 1954. When compared with the allowances recommended by the British Medical Association, it is found to be satisfactory. Supplies of nearly all the nutrients are, however, greater in the higher-than in the lowerincome groups. In the latter, supplies of protein are lower than the British Medical Association's recommended allowance for households, with total incomes of less than $230 \mathrm{~s}$. a week, and old-age pensioners may be somewhat short of iron. No data are available indicating that these deficiencies affect the health of the groups in question.

A chapter on geographical differences in food purchasing contains some interesting information. For example, in Scotland expenditure on cakes and biscuits was 36 per cent more than the average, and that on flour 40 per cent less than the average. Welsh households spent 30 per cent more than the average on flour, 60 per cent more on butter and 12 per cent less on cakes and biscuits.

Two new special studies were included in the 1958 survey. One deals with the effect on the household diet of the housewife's employment, which causes a change in the whole pattern of eating habits with more meals and snacks taken away from home. The results of this study were inconclusive, because of the difficulty in obtaining information about outside meals, and elaborate statistical treatment was scarcely warranted. The second special study was concerned with the food consumption of households dependent on one woman with no other wage-earner, and here the information collected was disturbing. The diets were in general less than the average in nutritive value, particularly in protein and calcium content, and, in the larger families so dependent, there was also a deficiency in calcium and riboflavin.

While the picture is on the whole satisfactory, the data for larger families check complacency. In households of two adults and two or more children, protein supplies are less than the British Medical Association's recommended allowances, and when there are four or more children the diet falls short of the allowance not only with respect to protein but also in calorie value and calcium and riboflavin content. The fact that these figures are an average for large families of all income groups means that consumption in the lower-income groups in this category is far less than the average for the whole groups of households sturyeyed. Joxce Dovarty

\section{IMMUNIZATION IN INDIA}

$I^{N}$ $\mathrm{N}$ a recent issue of the WHO Chronicle the possible part that could be played by wide-scale im. munization against disease in India, provided outside support is given, is considered (14, No. 11 ; November 1960).

About 13.5 per cent of India's 408 million inhabitants are infants and children of 4 and under ; about 25 per cent are between 5 and 15 years old.
Diphtheria, whooping cough and tetanus cause widespread morbidity and mortality in these age groups. Diphtheria-also rifo in rural areas-is responsible for between 2,000 and 5,000 admissions every year to hospitals in cities such as Calcutta and Bombay, and no fewer than 84 per cent of the cases are children between 2 and 10 years of age, while 11 per cent are infants. Investigations have shown that 